$R F E, 25,1941,383-398$ ) hay que tener en cuenta este dato lingüístico del pronombre personal lis, que fácilmente pudiera indicar la procedencia septentrional del autor.

University of Arizona.

DOLORES BRoWN

\title{
DE NUEVO SOBRE EL SONETO "NO ME MUEVE, MI DIOS..."
}

El crítico vacila, y debe vacilar, antes de aumentar lo ya dicho sobre cualquier obra clásica, y más cuando se trata de un poemita de catorce versos sobre el cual existe un estudio que llena todo un libro, aparte de los trabajos de dimensiones más modestas que se le han dedicado. Sin embargo, conviene de vez en cuando volver a dirigir la mirada sobre estas maravillas que siguen impresionándonos año tras año, generación tras generación, tanto para arrojar sobre ellas la luz de las investigaciones más recientes como para preguntarnos por qué una obra que lleva cuatrocientos años en el mundo es aún capaz de emocionarnos.

En lo que se refiere a las investigaciones, sobre todo las que estudian la génesis humana de nuestro poema, hace tiempo que contamos con varias teorías propuestas por hispanistas distinguidos que lo han relacionado con diversas corrientes espirituales del siglo xvi. Vamos a centrar nuestra atención sobre las de Marcel Bataillon y Leo Spitzer. Tomando como punto de partida el libro de Sister Mary C. Huff ${ }^{ \pm}$, Bataillon identifica el pensamiento espiritual del soneto con el movimiento del "beneficio de Jesucristo" 2 y descubre en el poema rasgos de indudable semejanza con pasajes del Beato Juan de Avila, de Juan de Valdés y del capuchino italiano Fra Bernardino Ochino, a propósito de la diferencia entre el amor puro y el amor interesado. "Espiritualidad de vanguardia - dice-, que fue la gran víctima del fndice español de 1559 porque su insistencia en la salvación por los méritos de Jesucristo olía entonces a cosa de «luteranos y alumbrados"; y así, después de hacer algunas conjeturas sobre el anonimato del soneto, sugiere la posibilidad de que el autor no se atreviera a firmar su obra por temor a la Inquisición ${ }^{3}$. La hipótesis parece verosímil, y los textos aducidos en su apoyo son muy fehacientes. No logró, sin embargo, convencer a Spitzer, quien, en una especie de réplica a las afirmaciones del hispanista francés, identificó la espiritualidad del soneto con la de los Ejercicios espirituales de San Ignació, aportando a su vez datos de gran fuerza probatoria.

1 The sonnet "No me mueve, mi Dios": its theme in Spanish tradition, Washington, D. C., 1948.

2 "El anónimo del soneto No me mueve, mi Dios", NRFH, 4 (1950), 254-269.

Reimpreso en Varia lección de clásicos españoles, Madrid, 1964, pp. 419-440.

3 Varia lección..., p. 427.

4 "No me mueve, mi Dios...", NRFH, 7 (1953), 608-617. 
Creo que existe la posibilidad de reconciliar hasta cierto punto las ideas aparentemente contradictorias de los dos ilustres eruditos, tarea siempre grata, a la cual nos dedicamos con toda buena voluntad. Si pensamos en los seres humanos que integraron las dos corrientes espirituales referidas, nos daremos cuenta en seguida de que tanto en una como en otra pululaban los conversos. Hace tiempo que se sabe por qué Juan de Valdés se encontraba en Italia y no en España, como también se sabe que muchos conversos se refugiaron en la Compañía. (Américo Castro ha puesto de relieve el hecho de que los tres primeros generales de la orden no hicieron distinción entre cristianos viejos y nuevos, y que el segundo general, el $P$. Diego Laínez, era de los nuevos. Esta actitud debe de haber motivado, según sugiere Castro, el elogio de los jesuitas por Cervantes en el Coloquio de los perrosit. Me parece que el denominador común entre la hipótesis de un autor alumbrado (Bataillon) y la de un autor jesuíta (Spitzer) es la de un autor converso, un hombre en cierto modo al margen de la espiritualidad de masas de su época, un hombre que, precisamente por ser "cristiano nuevo", se atiene a lo más fundamental y a lo más intimo de su nueva religión, y busca entre el hombre y Cristo una relación de amor que no necesita apoyarse en amenazas ni en promesas. Esta espiritualidad personalísima, como la de Santa Teresa de Jesús, tenía forzosamente que quedar fuera del ámbito de lo aprobado por la jerarquía eclesiástica. Así adquiere un sentido más concreto la insinuación de Bataillon: que el anonimato del soneto se explica por un deseo de salvaguardia personal.

Dejando el campo de la especulación, vamos a situarnos ahora en un terreno mucho más firme, el del texto. Adoptamos como punto de partida la división del poema en tres partes, propuesta por Spitzer. Según este esquema, la parte I, que coincide con el primer cuarteto, es una declaración de doctrina, asimilada por la memoria. La parte II, que incluye el segundo cuarteto y el primer verso del primer terceto, pone en juego la imaginación, creando una representación de Cristo crucificado que a su vez suscita un poderoso desbordamiento afectivo. La parte III, resultado del proceso de memoria, imaginación y emoción desarrollado en I y II, es una afirmación vigorosa de la voluntad humana en su capacidad de amar, o sea que la emoción de la parte II permite al poeta reafirmar su convicción (parte I) sobre una nueva y fortalecida base intelectual. Aceptada esta estructura en lo que se refiere al contenido "ideológico", intentemos ahora concentrarnos en las combinaciones de sonidos, pausas y acentos qne constituyen el as. pecto puramente fónico del soneto, a fin de ver cómo se integran lo fónico y lo ideológico en algo que podría llamarse "poético".

Lo primero que haremos será poner de relieve la importancia que tienen las vocales, sobre todo las acentuadas. Todos los versos llevan acento en la $6^{\mathbf{a}}$ sílaba, y la vocal que en ella domina es, con mucho,

5 Véase "Mi interpretación de la historia de los españoles", $L T, 1968$, núm. 59, 105-120, y "El Quijote, taller de existencialidad", ROcc, 18 (1967), 1-33, sobre todo pp. 19-22. 
la $e$ (nueve veces sobre catorce). La uniformidad así creada sufre una dramática ruptura en los versos 1,5 y 9 , que son justamente cabezas de estrofa, pues en ellos el acento en 6 a sílaba recae sobre la vocal $o$. Ahora bien, esta $o$ se encuentra en palabras relacionadas intimamente con las ideas rectoras del poema: Dios, señor, amor. Estas tres palabras forman una especie de espina dorsal, tanto fonética como "ideológica", en torno a la cual se organizan los demás fenómenos ${ }^{6}$.

Las tres partes señaladas por Spitzer se articulan mediante una estructura vocálica. En la primera estrofa, que corresponde a la parte I, todos los versos llevan acento en $6^{\mathrm{a}}$ y $10^{\mathrm{a}}$, y otro más, cuyo lugar varía (3a, 2a, 3a y $4^{a}$ ). Hay, pues, tres acentos de intensidad en cada verso, lo cual da a la estrofa un ritmo regular que sirve como de apoyo a la estructura paralelística de la sintaxis. Pero en el comienzo de la segunda estrofa observamos algo curioso. En lugar de tres, son cinco las sílabas acentuadas: "Tú me muéves, señór; muéveme el vérte". El esquema rítmico establecido en el primer cuarteto se ha quebrado. Este endecasílabo extraño, no sólo por su acentuación poco frecuente en sí, sino también por su carácter distinto frente a los antecedentes, nos obliga a detener nuestra lectura. Se trata de un fenómeno nuevo, que abarca tanto el nivel ideológico (comienzo de la parte II) como el fónico. En otras palabras, el paso de la parte I a la parte II queda marcado poéticamente por un cambio abrupto en el ritmo del endecasílabo.

El final de la parte II está señalado por un cambio rítmico análogo. Recordemos que los límites de esta parte no coinciden con los del segundo cuarteto, sino que en ella se incluye también el primer verso del primer terceto. Pues bien, en este verso, que resume los efectos de la crucifixión, descrita en el segundo cuarteto, encontramos de nuevo cinco sílabas acentuadas: "Muéveme, en fín, tu amór, y en tál manéra". Con excepción del verso primero, del que ya hablamos, predomina en la parte II, al igual que en la $\mathrm{I}$, un ritmo de tres sílabas acentuadas por verso, de modo que este verso final que de repente rompe el esquema establecido nos recuerda el primero, también de acentuación "anómala". Así, el poeta ha enmarcado la parte central, cumbre emotiva de su creación, con dos versos cuya acentuación los aparta en forma dramática de los otros, constituyendo una nítida unidad fónica que coincide exactamente con el carácter esencial de la parte II como eslabón necesario entre el pensamiento de la parte I y el de la parte III.

Conviene ahora que nos detengamos ante el prodigioso acto de imaginación que engendra toda la emoción de la parte II. Se trata, como todo el mundo ha visto, de una representación imaginativa de Cristo crucificado, que debe remontarse, como Bataillon ha sugerido, a una descripción semejante hecha por el Beato Ávila. La influencia me parece innegable; sin embargo, no tenemos aquí una descripción estática de una figura cuya agonía nos produce honda emoción. Des-

- Hay otras dos excepciones del predominio de la $e$ : el verso 6, donde la vocal acentuada en 6? es $u$ (la $u$ de una nueva palabra clave: cruz), y el verso 12, cabeza de la última estrofa, donde el acento en $6^{\text {a }}$ recae sobre una $a$ (dar). De hecho, esta última estrofa tiene un carácter recapitulativo, que la distingue de las tres anteriores, de manera que la diferencia "vocálica" acentúa esa diferencia de carácter. 
cripciones estáticas las hay, y mejores, en cualquier iglesia. No se trata aquí de una descripción, sino de una narración. El poeta se ha proyectado hacia el pasado, hasta el momento mismo de la crucifixión, y se ha puesto a referirnos, en orden cronológico, los sucesos. En otras palabras, cuando dice: "muéveme el verte / clavado en una cruz y escarnecido", está asistiendo mentalmente a la crucifixión y contando su reacción al ver cómo clavan a Gristo cn la cruz y cómo lo insultan; cuando dice: "muéveme ver tu cuerpo tan herido", está refiriéndose concretamente a la herida abierta en ese momento en su costado; y cuando dice: "muévenme tus afrentas y tu muerte", está contemplando las últimas agonías y la muerte en que culminan. Se trata, pues, de una progresión cronológica en la que cada suceso provoca una respuesta emotiva en el poeta ${ }^{\tau}$. No nos describe sus reacciones frente a una serie de aspectos iconográficos de la crucifixión. Lo que nos describe es una experiencia personal: su com-pasión frente a la pasión y muerte de Cristo. No cabe ir más allá. Estamos en el eje de todo el cristianismo, el sacrificio que, ritualizado, se repite diariamente en millares de iglesias católicas. Mediante un poderoso esfuerzo imaginativo, el poeta ha podido vivir, paso a paso, la crucifixión en toda su estrujante novedads.

El verso 9 es un análisis de la emoción, que hasta ahora ha permanecido sin especificar, producida por el acto imaginado-vivido: "Muéveme, en fin, tu amor..." Ya hemos estudiado la estructura rítmica de este verso; ahora podemos apreciar mejor su carácter de resumen, combinando nuestro análisis rítmico con lo que acabamos de decir sobre su significado. Compárese el primer verso de la parte II: "T $u$ me muéves, señór...", con este último: "Muéveme, en fín, tu amór..." Observamos, además del ya señalado aumento en el número de sílabas acentuadas, que el eje rítmico está siempre en la 6a sílaba, que las palabras en que ésta se sitúa (señor, amor) riman entre sí, y que también son las más significativas de la parte II: señor, el Dios-hombre que aceptó la muerte, y amor, resultado último de la sacudida emotiva

7 Spitzer, cuyas agudas observaciones de pequeños detalles nunca dejan de ser significativas, pone ya de relieve la impresión de novedad, de algo visto por primera vez, que produce en el lector la expresión "una cruz", en vez de "la [bien conocida] cruz".

s Es de notar que también Ramón Llull se detuvo ante el hecho de la crucifixión para inspirarse en el amor puro de Cristo. Helmut Hatzfeld, en Trad, 4 (1946), p. 345, sugiere una posible influencia luliana sobre nuestro soneto. Llull evoca los sucesos en un orden cronológico semejante al que hemos visto en "No me mueve...": "Vostres braces et mans foren clavellats..., vostre gloriós costat fo nafrat..." Pero al introducir esta escena emocionante, no dice nunca haberla visto ni imaginado: "Jesu Xrist Senyor! Adorar, amar et contemplar vos volria en la vostra santa passió per ço que de vos me pogués enamorar..." Todo esfuerzo imaginativo queda truncado por este verbo en condicional. Llull querria contemplar a Cristo en la cruz, pero, por lo visto, le es imposible. Su narración se convierte así en una enumeración de hechos consabidos, sin relieve emotivo especial. El gran acierto de nuestro anónimo poeta ha sido presenciar imaginativamente el acto de la crucifixión y comunicar sus impresiones, sus reacciones, a medida que se verifican las acciones sucesivas. Fuerza afectiva de la evocación luliana: casi nula; del "No me mueve...": prodigiosa. 
que los dos versos encierran. Es difícil imaginar cómo hubiera podido el poeta enmarcar mejor esta parte de su creación y darle un lugar especialmente destacado frente a las partes que la rodean.

Las partes I y III, como ha indicado Spitzer, comparten el rasgo de ser formulaciones intelectuales, dentro de las cuales se encierra la parte II, cumbre emotiva. Esta cumbre, sin embargo, no es el momento máximo del poema. En realidad, tanto II como I sirven para posibilitar III, "afirmación vigorosa" de la voluntad humana. Dada la importancia del sistema de vocales acentuadas que hemos observado, cabe esperar que esta parte III se distinga de las dos anteriores no sólo con respecto al tono psicológico-intelectual, sino también en lo que se refiere a la estructura fónica. Ya Spitzer se fijó en la repetición de sonidos, sobre todo de sonidos consonánticos, que caracteriza la parte III y le da un carácter de "armadura de acero martillado". Quisiera ahora ampliar esta visión hasta abarcar todo el soneto, y mostrar cómo este elemento pasa, de fenómeno meramente "textural", a ser fundamento de la estructura total.

Lo que más llama la atención del lector en este sentido es la abundancia de diptongos acentuados que pueden observarse a lo largo del soneto. De 47 acentos de intensidad, 22 recaen sobre diptongos. Salvo un caso de ió (Dios, verso 1), todos los demás son ué y ié. El grupo ué aparece nueve veces, siempre en las partes I y II (no hay ué en la parte III). Esta distribución está perfectamente de acuerdo con la división temática que ya hemos observado, o sea el hecho de que las dos primeras partes constituyen una preparación psicológica para la parte final. En cuanto al diptongo $i e ́$, aparece doce veces, siempre en las partes I y III. De estos doce casos, sólo tres pertenecen a la parte I, y los nueve restantes se concentran, adensándose, en la parte III. Esta distribución, complementaria respecto a la del diptongo $u e ́$, coincide con el cambio de enfoque psicológico que se marca entre las partes I y II por un lado y la parte III por otro, al mismo tiempo que recuerda ligeramente la semejanza observada por Spitzer entre I y III en cuanto a formulaciones intelectuales. El diptongo se encuentra en I en cielo y en infierno, palabras que se repiten en III, de modo que la repetición del sonido va ligada a la del valor semántico de la palabra. Se establece así una tensión unificadora entre I y III, intelectualmente parecidas pero profundamente disímiles por el tiempo verbal, por la posición del pronombre te y sobre todo por el vigor de la afirmación, positiva en III, del amor humano en contraste con la doble negación de I. A esta tensión se une, respaldándola en el nivel puramente fónico, la distribución del diptongo $i e ́$.

Sería absurdo afirmar que un sonido, de por sí, tiene sentido lexicográfico o psicológico, o que la repetición de un sonido, su distribución a través de un poema, puede determinar la orientación total de éste. Sin embargo, los detalles fonéticos (número de sílabas acentuadas en cada verso, distribución de sonidos claves en lugares estratégicos), considerados en función de los demás elementos del poema (léxico, sintaxis, organización del pensamiento), crean uno como sustrato sensorial a través del cual el poema como entidad artística va insinuándose 
en la conciencia de cada generación de lectores. Ahí debe residir algo del encanto del soneto "No me mueve, mi Dios...", que sigue "moviéndonos" cuatrocientos años después de creado.

Carroll B. Johnsox

University of California (Los Angeles).

\section{LA EXPULSIÓN DE LOS MORISCOS EN EL PERSILES}

Lo único incuestionable que se puede afirmar sobre la fecha de redacción del Persiles, publicado en 1617 , es que incuestionablemente se desconoce. Respecto a este punto, no existen más que dos criterios, uno el mantenido por Schevill y Bonilla, el otro por Max Singleton. Los primeros expusieron el suyo -canalizando opiniones anterioresen la edición que de la novela hicieron en 19l4; Singleton lo hizo en un trabajo aparecido en 1947 con el título de "El misterio del Persiles"'. Agreguemos que la opinión de los primeros es la unánimemente aceptada por los manuales y por quienes no han estudiado la novela desde este ángulo; la del segundo no ha sido admitida por nadie.

El Persiles se compuso, según Schevill y Bonilla, después de 1609, y ello por tres razones: a) las afirmaciones que Cervantes hace en 1613, 1614 y dos veces en 1615 acerca de su novela, las cuales nos indican que trabajaba en ella por esos años; b) la alusión que hace en el libro III a la expulsión de los moriscos, acontecimiento ocurrido en 1609; c) la fecha de los Comentarios del Inca (1609), que Cervantes usó, al parecer, para su novela.

La teoría de Singleton es bastante diferente. Según él, la novela se compuso en los decenios de 1560,1570 y 1580 , aunque no queda claro si se refiere a una de estas décadas sólo o a todas ellas. Como sea, no cabe duda sobre su conclusión: el Persiles "antedates Galatea by a good ten or fifteen years". Singleton basa esta afirmación en hechos muy diversos que sería largo de resumir, aunque de su trabajo se puede afirmar lo siguiente: a razones aceptables se aúnan otras que sólo se pueden calificar de catastróficas.

Una de las razones aceptables que Singleton maneja para impugnar la fecha de 1609 es el sostener que Cervantes no alude a la expulsión de los moriscos como acontecida. "Nowhere in the Persiles passage does Cervantes make anything like a reference to the expulsion itself".

La cuestión de la fecha del Persiles es muy compleja y requeriría muchas páginas, muchas más que las apresuradas de Schevill y Bonilla y las apasionadas de Singleton. Siquiera sea por definirnos, agreguemos que a nuestro juicio la tesis de los unos como la del otro es errónea, aunque algo hay de verdad en ambas. Para decirlo sin rodeos: creemos que el Persiles tiene unas partes anteriores a 1609 y otras posteriores.

1 En Realidad, Buenos Aires, 2 (1947), 237-253. Incluyeron la versión inglesa M. BenARdete y A. Flores en Cervantes across the centuries, New York, 1947. 